\title{
Preservation of retinal structure and function after cilioretinal artery occlusion: a case report
}

\author{
This article was published in the following Dove Press journal: \\ International Medical Case Reports Journal \\ II February 2016 \\ Number of times this article has been viewed
}

\author{
Craig J Brown \\ The Eye Center, Fayetteville, AR, USA
}

Correspondence: Craig J Brown

The Eye Center, 594 East Millsap Road,

Fayetteville, AR 72703, USA

$\mathrm{Tel}+\mathrm{I} 4794422020$

Fax + I 4795213988

Email cjbrown 1234@sbcglobal.net

\begin{abstract}
Cilioretinal artery occlusion is a cause of sudden, often catastrophic loss of central vision. There are no established effective treatments. Recently, a patient presented 24 hours after a cilioretinal artery occlusion, following a cardiac catheterization prior to which her blood thinners had been discontinued. Lacking an effective way to address the severe retinal ischemic oxidative stress, she was offered, under compassionate use, a multivitamin complex designed to address retinal ischemia and oxidative stress. Significant components of this product are L-methylfolate and $n$-acetyl cysteine. The patient experienced a rapid unexpected improvement in vision and preservation of retinal structure, suggesting that marked improvement in retinal artery occlusions outcomes may be possible as late as 24 hours postocclusion. This is the third reported case of cilioretinal artery occlusion associated with cardiac catheterization.
\end{abstract}

Keywords: retinopathy, MTHFR, homocysteine, L-methylfolate, stroke, NAC

\section{Introduction}

Cilioretinal artery occlusion involving the macula typically causes a sudden catastrophic loss of vision and subsequent destruction of inner retinal neurons. Cilioretinal artery occlusion has no established effective treatment. Hopeful observation might best characterize the ophthalmologists' recommendations to the stricken patients. ${ }^{1}$

An 83-year-old Caucasian female sustained a sudden loss of vision in her left eye 2 hours after a cardiac catheterization before resuming her customary anticoagulant for atrial fibrillation. For 24 hours, there was a progressive decline in central vision that began to reverse after beginning a new medical food developed for addressing retinal ischemia associated with the common dysfunctional polymorphism of the gene methylenetetrahydrofolate reductase (MTHFR) C677T, which interferes with retinal folate metabolism.

After 4 months, her vision had improved from 20/80 to 20/40, and optical coherence tomography (OCT) scanning showed unexpected preservation of the inner retinal neurons compared to other published cases.

Retinal ischemia is the final common pathway for many vascular retinopathies causing vision loss. The ability of clinicians to reduce ischemia has a profound effect on structural preservation and vision preservation.

\section{Case presentation}

A concerned cardiologist recently requested an urgent consultation for one of his patients who had experienced a loss of vision 2 hours after an uneventful cardiac catheterization. Prior to her catheterization, she had been taken off blood thinners, 
prescribed for atrial fibrillation. The cardiologist was informed about this 24 hours after the vision loss, and immediately requested ophthalmologic consult on an emergency basis. She was examined by the author (CJB), an ophthalmologist, later that same day.

The patient was an 83-year-old Caucasian female of European descent, who was in moderate distress. She noted that after the catheterization, she had been fine for 2 hours, but as she prepared to leave the hospital, her left eye suddenly developed a lavender central blind spot, which over the next 24 hours progressed to a dark smoky blue scotoma with complete loss of vision within the scotoma.

She had a history of cataract, amaurosis fugax, labile hypertension, and atrial fibrillation for which she ordinarily took lisinopril and warfarin. In preparation for her cardiac catheterization, she had discontinued her warfarin for several days. She had now resumed it. Her sedimentation rate was 20.0, Westergren method, and her C-reactive protein was 0.8 . She had no history, signs, or symptoms suggestive of temporal arteritis or giant cell arteritis.

On examination, the patient's best visual acuity in her left eye (VA OS [oculus sinister]) was 20/80, and she had a cilioretinal artery occlusion with edema involving the maculopapular bundle and macula of the left eye, which was documented photographically, albeit through a moderately dense cataract (Figure 1A). There was no associated central vein occlusion.

She related that her vision had declined steadily since the initial event. At first, she could still see a cloudy image, but now there was a dark purple cloud getting denser and denser. She feared further permanent vision loss was imminent.

Faced with a 24-hour-old progressive nonarteritic ischemic infarct of the macular region where there was little established effective therapy to recommend, she was offered Ocufolin $^{\mathrm{TM}}$ (Global Healthcare Focus, LLC, Montgomery, AL, USA), a new medical food developed to address retinal

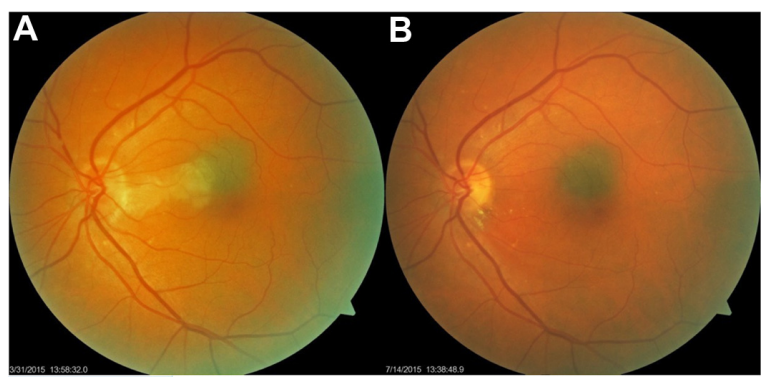

Figure I (A) shows acute cilioretinal artery occlusion after 24 hours following cardiac catheterization. (B) shows resolution of the retinal edema, and residual retinal exudates, 14 weeks later.

Notes: Note deep retinal edema extending into the fovea of the left eye. Present also is a choroidal nevus of the macula. ischemia and associated oxidative stress. She accepted and took one capsule daily for 5 weeks.

After 5 weeks, her VA OS corrected to 20/40. She stated that she could see through a faint residual lavender cloud, enough for most activities except reading. She also stated that there was ongoing steady improvement, which began a few hours after beginning Ocufolin ${ }^{\mathrm{TM}}$. Examination revealed resolution of retinal edema with some dependent retinal exudate and mild temporal optic nerve pallor. At this time, her dosage was advanced to two capsules Ocufolin ${ }^{\mathrm{TM}}$ daily.

After 3 months, her best VA OS remained 20/40, and the subjective purple haze was much diminished. She was able to perform all normal functions with the left eye, except those requiring fine resolution (Figure 1B).

After 4 months, she reported continued visual improvement subjectively. An OCT scan demonstrated a narrow line of macular thinning corresponding to the central zone of the cilioretinal artery occlusion, but with substantial preservation on either side of it (Figure 2). Cross-sectional imaging showed surprising preservation of the ganglion cell layer and inner nuclear layer, considering that more than 24 hours had elapsed before addressing the retinal ischemia (Figure 3). After 8 months her vision recovered to $20 / 25$ with a small paracentral scotoma.

Testing revealed she carried the common MTHFR C677T genotype, which decreases methylation of folate and increases oxidative stress and ischemic events..$^{2-4}$

She had better vision, less ganglion cell loss, and less visible optic nerve pallor than would be expected at that point. She continues to be under observation taking the Ocufolin ${ }^{\mathrm{TM}}$. The Washington Regional Institutional Review Board advised that this case report did not require approval for publication; written informed consent was obtained from the patient.

\section{Discussion}

The incidence of retinal artery embolism detectable immediately after cardiac catheterization has been reported to

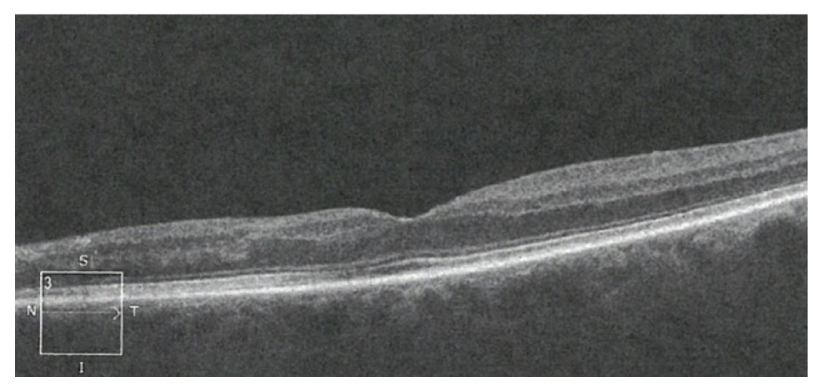

Figure 2 OCT scan of retina in cross-section showing loss of RPE and deep retinal structures nasal to the fovea 14 weeks after the occlusion.

Abbreviations: OCT, optical coherence tomography; RPE, retinal pigment epithelium. 


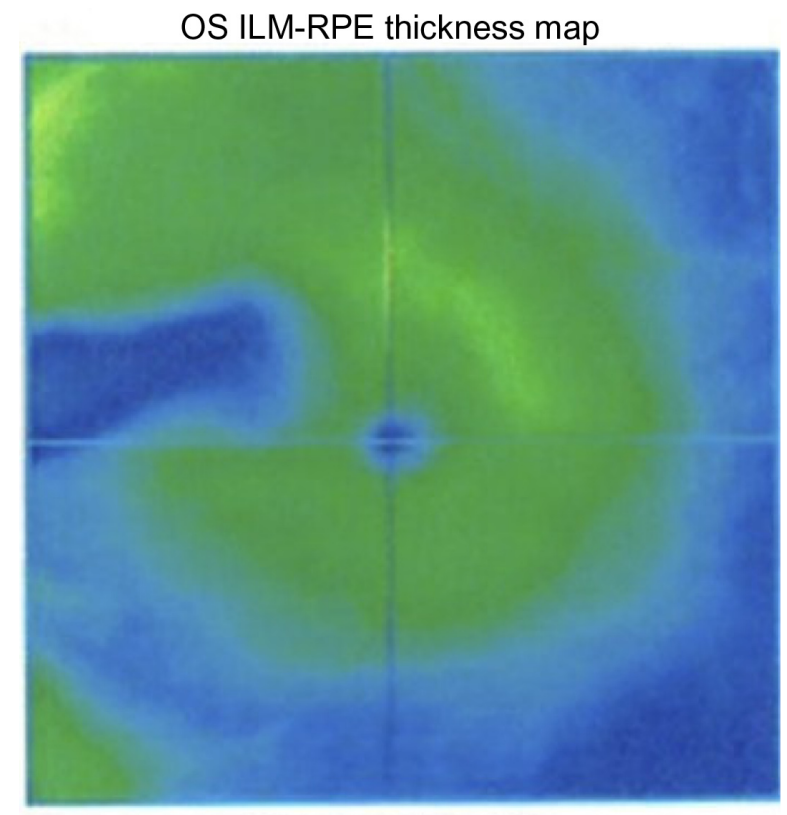

Fovea: 250,67

Figure 3 OCT scan of the macula showing loss of retinal pigment epithelium 14 weeks after the occlusion.

Abbreviations: OS, oculus sinister; ILM, internal limiting membrane; RPE, retinal pigment epithelium; OCT, optical coherence tomography.

be between $2 \%$ and $6 \%$. Despite such a high frequency of retinal embolism, they are rarely noticed and vision is rarely affected. Cilioretinal artery occlusion is an uncommon form of retinal artery occlusion and rarely is a complication of coronary artery catheterization..$^{5-9}$

A patient who has lost vision due to a retinal artery occlusion in the postacute phase has few options to protect the retina and restore functional vision. After investigation for causation, initiation of blood thinners and perhaps hyperbaric oxygen therapy, there is nothing left for an eye specialist to do except wait with the patient in a hopeful attitude. ${ }^{6,10-13}$

Brown and Shields ${ }^{5}$ published a series of 187 retinal artery occlusions. Only 5\% were cilioretinal artery occlusions. Cella and Avila ${ }^{14}$ published a two-case report from Brazil wherein the OCT of a branch retinal artery occlusion (BRAO) showed near complete retinal atrophy of the macula. Parcero et $\mathrm{al}^{15}$ published a similar case report of BRAO, also from Brazil. Both Cella and Avila ${ }^{14}$ and Parcero et $\mathrm{al}^{15}$ demonstrated that retinal artery occlusion featured advanced loss of the ganglion cell and inner nuclear layers. Hayreh et $\mathrm{al}^{16}$ showed, in elderly hypertensive monkeys, that a central retinal artery occlusion (CRAO) of up to 97 minutes showed no permanent damage, but beyond 4 hours resulted in massive irreversible damage to the ganglion cell and inner nuclear layer.

Saxena et $\mathrm{al}^{17}$ reported a case of CRAO with retinal thickness measurements on days $3,7,30$, and 90 . An edematous increase in retinal thickness was noted on day 3 . On day 7 , there was a marked retinal thickness decrease suggesting retinal reperfusion injury. Retinal thickness returned to normal on day 30, and retinal atrophy was noted on day 90 . They propose that reperfusion around day 7 might, as in other tissues, be associated with reperfusion injury and eventual retinal atrophy. This suggests that there might be a window for prevention of retinal perfusion injury before day 7 , which might prevent retinal atrophy at day $90 .{ }^{17}$

Mason et $\mathrm{al}^{18}$ reported on a series of $54 \mathrm{BRAO}$ patients, showing that initial acuity was the best predictor of final acuity. Only $14 \%$ of patients initially $20 / 100$ or worse returned to $20 / 40 .^{18}$

Kreis et $\mathrm{al}^{7}$ reported on 100 patients undergoing cardiac catheterization with preprocedural and postprocedural retinal imaging. They found $2 \%$ of the patients had new retinal emboli in the right superior temporal retinal arterioles. None of them had vision loss. Kojuri et $\mathrm{al}^{8}$ reported on 300 patients, with $6 \%$ having retinal emboli. Only one of the 300 experienced symptoms. ${ }^{7,8}$

Recently, a personalized medical food, Ocufolin ${ }^{\mathrm{TM}}$, has been developed for addressing the underlying issues of genetically dysfunctional folate metabolism and the resultant increased oxidative stress complicating retinal ischemia.

Ocufolin $^{\mathrm{TM}}$ specifically addresses the ischemic consequences of the C677T polymorphism of the MTHFR gene, which is present in $40 \%$ of the Caucasian American population, 50\% of Europeans (UK), 50\% of Latin Americans, and a lower percentage in African-Americans and AsianAmericans. ${ }^{19-23}$

The C677T polymorphism has been linked to several other retinal ischemic conditions, including hypertensive retinopathy, thrombophilic retinal artery occlusion as well as branch and CRAOs, ischemic cerebral stroke, and small vessel disease..$^{2,24-31}$

The C677T polymorphism results in an impaired ability to produce plasma L-methylfolate due to an impaired sensitivity to riboflavin (vitamin B2). L-methylfolate is the active form of folate and essential to cellular homeostasis and tissue repair. MTHFR C677T is associated with elevated blood pressure and elevated homocysteine, which are both known to damage small vessels. The downstream consequences of this are seen as increased cardiovascular disease and increased small vessel disease of the central nervous system, especially the retina. Increased oxidative stress, homocysteine, and inflammation are causes of arterial and venous occlusive disease with concomitant capillary dropout, damage to ganglion cells, bipolar cells, and photoreceptors; all of which are cascading effects caused by limited perfusion of cells that natively have very high metabolic activity. 3,32-34 
Patients with the dysfunctional allele MTHFR C677T are more likely to develop hyperhomocysteinemia, neurovascular small vessel disease of the central nervous system, ischemia, and stroke. ${ }^{4}$

Retinal ischemia can be addressed by optimizing specific micronutrients that lower homocysteine and promote glutathione. Additionally, homocysteine is directly toxic to retinal ganglion cells and photoreceptors, so lowering homocysteine is essential. ${ }^{35-37}$

Ocufolin ${ }^{\mathrm{TM}}$ incorporates L-methylfolate (Metafolin ${ }^{\circledR}$, Merck KGaA, Darmstadt, Germany), B2 (riboflavin), B6, and methyl B12. Riboflavin promotes the methylation of tetrahydrofolate ultimately yielding L-methylfolate. L-methylfolate and methyl B12 act to increase the methylation of homocysteine, thus converting it to methionine. Ocufolin ${ }^{\mathrm{TM}}$ additionally contains vitamin $\mathrm{C}$, vitamin $\mathrm{D}$, selenium, zinc, copper, lutein, and zeaxanthin that recycle spent glutathione, as well as $n$-acetyl cysteine (NAC). NAC is a glutathione precursor that readily crosses the blood/brain and blood/retinal barriers. Under ischemic conditions, it has an antiapoptotic effect on neurons of the brain and retinal ganglion cells and retinal pigment epithelium. NAC and thiamin have been shown to be neuroprotective to the brain and retina under ischemic conditions by reducing oxidative stress in the small vessels and retinal tissues. In particular, it might be most effective if initiated prior to the reperfusion stage occurring between the third and seventh day. ${ }^{38-43}$

In addition, systemic hypertension can be a result of hyperhomocysteinemia associated with the MTHFR C677T polymorphism and may be mitigated by folate supplementation. ${ }^{44}$

A single case report is not proof of concept, but the patient's experience is supportive. She began improving within hours after her first dose of Ocufolin ${ }^{\mathrm{TM}}$, and she continued to improve steadily for at least 8 months, returning to $20 / 25$ vision with a small central scotoma. Significantly better than expected preservation of all layers of the retina and its architecture was noted at 4 months, in contrast to the patients reported by Cella and Avila, ${ }^{14}$ Parcero et al, ${ }^{15}$ or the monkey subjects of Hayreh et al. ${ }^{16}$

A specific supplementation with selected micronutrients designed for the ischemic consequences of the MTHFR C677T polymorphism might be an interesting new approach, particularly for patients with that common inborn error of metabolism, which affects a large percentage of patients with European and Latin American heritage. Ideally, it would be started as near to the onset as possible; however, our patient experienced the benefits of increased visual acuity and remarkable neuroprotection despite waiting over 24 hours to address the situation.

\section{Conclusion}

Our case, in a patient with the common MTHFR C677T polymorphism, contrasts with previous case reports of retinal artery occlusion. This patient had better recovery of vision, and better than expected preservation of the inner retinal layers of the nasal macula, especially the ganglion cell layer, possibly due to protection from ischemia by NAC and other ingredients addressing downstream effects of genetic methylation impairment.

It is conceivable that better results could have occurred with earlier intervention. Nonetheless, her improvement is remarkable. The use of Ocufolin ${ }^{\mathrm{TM}}$, a new medical food designed to address the ischemic consequences of this common inborn error of metabolism, appears to have been successful in this case. A proper trial of this approach is to be hoped for in the future.

\section{Acknowledgments}

The author would like to acknowledge and thank Martin Ulmann, of Aprofol AG, for important discussions on the biochemistry of L-methylfolate and the history of its clinical use in Europe. His assistance in revising this manuscript for publication is greatly appreciated.

\section{Author contributions}

Craig J Brown performed all clinical work and manuscript preparation for this article, and provided all images used.

\section{Disclosure}

Craig J Brown, MD, FACS, is a consultant and stockholder with Global Healthcare Focus, the maker of Ocufolin ${ }^{\mathrm{TM}}$. The author reports no other conflicts of interest in this work.

\section{References}

1. Hayreh SS, Podhajsky PA, Zimmerman MB. Branch retinal artery occlusion: natural history of visual outcome. Ophthalmology. 2009; 116(6):1188-1194. e1-e4.

2. Kumar A, Kumar P, Prasad M, et al. Association of C677T polymorphism in the methylenetetrahydrofolate reductase gene (MTHFR gene) with ischemic stroke: a meta-analysis. Neurol Res. 2015;37(7): 568-577.

3. Födinger M, Hörl WH, Sunder-Plassmann G. Molecular biology of 5,10methylenetetrahydrofolate reductase. J Nephrol. 2000;13(1):20-33.

4. Hassan A, Hunt BJ, O'Sullivan M, et al. Homocysteine is a risk factor for cerebral small vessel disease, acting via endothelial dysfunction. Brain. 2004;127(Pt 1):212-219.

5. Brown GC, Shields JA. Cilioretinal arteries and retinal arterial occlusion. Arch Ophthalmol. 1979;97(1):84-92. 
6. Loewenstein A, Goldstein M, Roth A, Lazar M. Cilioretinal artery occlusion during coronary catheterization. Acta Ophthalmol Scand. 1999;77(6):717-718.

7. Kreis AJ, Nguyen T, Rogers S, et al. Acute retinal arteriolar emboli after cardiac catheterization. Stroke. 2008;39(11):3086-3087.

8. Kojuri J, Mehdizadeh M, Rostami H, Shahidian D. Clinical significance of retinal emboli during diagnostic and therapeutic cardiac catheterization in patients with coronary artery disease. BMC Cardiovasc Disord. 2011;11:5

9. Meyer CH, Holz FG. Images in clinical medicine. Blurred vision after cardiac catheterization. $N$ Engl J Med. 2009;361(24):2366.

10. Stoffelns BM. Isolated cilioretinal artery occlusion - clinical findings and outcome in 31 cases. Klin Monbl Augenheilkd. 2012;229(4): 338-342. German

11. Weiss JN. Hyperbaric oxygen treatment of retinal artery occlusion. Undersea Hyperb Med. 2010;37(3):167-172.

12. Celebi AR, Kadayifcilar S, Eldem B. Hyperbaric oxygen therapy in branch retinal artery occlusion in a 15-year-old boy with methylenetetrahydrofolate reductase mutation. Case Rep Ophthalmol Med. 2015;2015:640247.

13. Cope A, Eggert JV, O’Brien E. Retinal artery occlusion: visual outcome after treatment with hyperbaric oxygen. Diving Hyperb Med. 2011;41(3):135-138

14. Cella W, Avila M. Optical coherence tomography as a means of evaluating acute ischaemic retinopathy in branch retinal artery occlusion. Acta Ophthalmol Scand. 2007;85(7):799-801.

15. Parcero CM, Freitas Bde P, Marback EF, Maia Ode O Jr, Marback RL. Optical coherence tomography findings in acute phase of branch retinal artery occlusion: case report. Arq Bras Oftalmol. 2010;73(2): 189-192.

16. Hayreh SS, Zimmerman MB, Kimura A, Sanon A. Central retinal artery occlusion. Retinal survival time. Exp Eye Res. 2004;78(3):723-736.

17. Saxena S, Mishra N, Meyer $\mathrm{CH}$, Akduman L. Ischaemiareperfusion injury in central retinal artery occlusion. BMJ Case Rep. 2013;2013:201415.

18. Mason JO 3rd, Shah AA, Vail RS, et al. Branch retinal artery occlusion: visual prognosis. Am J Ophthalmol. 2008;146(3):455-457.

19. Wilcken B, Bamforth F, Li Z, et al. Geographical and ethnic variation of the $677 \mathrm{C}>\mathrm{T}$ allele of 5,10 methylenetetrahydrofolate reductase (MTHFR): findings from over 7000 newborns from 16 areas world wide. J Med Genet. 2003;40(8):619-625.

20. Botto LD, Yang Q. 5,10-Methylenetetrahydrofolate reductase gene variants and congenital anomalies: a HuGE review. Am J Epidemiol. 2000;151(9):862-877.

21. Guéant-Rodriguez RM, Guéant JL, Debard R, et al. Prevalence of methylenetetrahydrofolate reductase $677 \mathrm{~T}$ and $1298 \mathrm{C}$ alleles and folate status: a comparative study in Mexican, West African, and European populations. Am J Clin Nutr. 2006;83(3):701-707.

22. Schneider JA, Rees DC, Liu YT, Clegg JB. Worldwide distribution of a common methylenetetrahydrofolate reductase mutation [Letter to the Editor]. Am J Hum Genet. 1998;62:1258-1260.

23. Qi Z, Hoffman G, Kurtycz D, Yu J. Prevalence of the C677T substitution of the methylenetetrahydrofolate reductase (MTHFR) gene in Wisconsin. Genet Med. 2003;5(6):458-459.

24. Ravera M, Viazzi F, Berruti V, et al. 5,10-Methylenetetrahydrofolate reductase polymorphism and early organ damage in primary hypertension. Am J Hypertens. 2001;14(4 Pt 1):371-376.

25. Heifetz M, Birk RZ. MTHRF C677T polymorphism affects normotensive diastolic blood pressure independently of blood lipids. Am J Hypertens. 2015;28(3):387-392.

26. Salomon O, Huna-Baron R, Moisseiev J, et al. Thrombophilia as a cause for central and branch retinal artery occlusion in patients without an apparent embolic source. Eye (Lond). 2001;15(Pt 4):511-514.
27. Gao W, Wang YS, Zhang P, Wang HY. MTHFR C677T mutation in central retinal vein occlusion: a case-control study in Chinese population. Thromb Res. 2008;121(5):699-703.

28. Risse F, Frank RD, Weinberger AW. Thrombophilia in patients with retinal vein occlusion: a retrospective analysis. Ophthalmologica. 2014;232(1):46-52.

29. Russo PD, Damante G, Pasca S, Turello M, Barillari G. Thrombophilic mutations as risk factor for retinal vein occlusion: a case-control study. Clin Appl Thromb Hemost. 2015;21(4):373-377.

30. Mrad M, Wathek C, Saleh MB, et al. Association of methylenetetrahydrofolate reductase (A1298C and C677T) polymorphisms with retinal vein occlusion in Tunisian patients. Transfus Apher Sci. 2014;50(2): 283-287.

31. Huo Y, Li J, Qin X, et al. Efficacy of folic acid therapy in primary prevention of stroke among adults with hypertension in China: the CSPPT randomized clinical trial. JAMA. 2015;313(13):1325-1335.

32. Yu DY, Cringle SJ, Yu PK, Su EN. Intraretinal oxygen distribution and consumption during retinal artery occlusion and graded hyperoxic ventilation in the rat. Invest Ophthalmol Vis Sci. 2007;48(5):2290-2296.

33. Yu DY, Cringle SJ. Oxygen distribution and consumption within the retina in vascularised and avascular retinas and in animal models of retinal disease. Prog Retin Eye Res. 2001;20(2):175-208.

34. van der Put NM, Gabreëls F, Stevens EM, et al. A second common mutation in the methylenetetrahydrofolate reductase gene: an additional risk factor for neural-tube defects? Am J Hum Genet. 1998;62(5): 1044-1051.

35. Sowbhagya HN, Kothari M, Kumar LK, Nikhil N. Ocular manifestations of hyperhomocysteinemia and their response to therapeutic modalities. IJSS. 2015;3(3):55-59.

36. Ganapathy PS, Perry RL, Tawfik A, et al. Homocysteine-mediated modulation of mitochondrial dynamics in retinal ganglion cells. Invest Ophthalmol Vis Sci. 2011;52(8):5551-5558.

37. Chang HH, Lin DP, Chen YS, et al. Intravitreal homocysteine-thiolactone injection leads to the degeneration of multiple retinal cells, including photoreceptors. Mol Vis. 2011;17:1946-1956.

38. Shahripour RB, Harrigan MR, Alexandrov AV. N-acetylcysteine (NAC) in neurological disorders: mechanisms of action and therapeutic opportunities. Brain Behav. 2014;4(2):108-122.

39. Schimel AM, Abraham L, Cox D, et al. N-acetylcysteine amide (NACA) prevents retinal degeneration by up-regulating reduced glutathione production and reversing lipid peroxidation. Am J Pathol. 2011;178(5):2032-2043.

40. Gerona G, López D, Palmero M, Maneu V. Antioxidant N-acetylcysteine protects retinal pigmented epithelial cells from long-term hypoxia changes in gene expression. J Ocul Pharmacol Ther. 2010; 26(4):309-314.

41. Yang L, Tan P, Zhou W, et al. N-acetylcysteine protects against hypoxia mimetic-induced autophagy by targeting the HIF-1 $\alpha$ pathway in retinal ganglion cells. Cell Mol Neurobiol. 2012;32(8):1275-1285.

42. Keene KL, Chen WM, Chen F, et al. Genetic associations with plasma B12, B6, and folate levels in an ischemic stroke population from the Vitamin Intervention for Stroke Prevention (VISP) Trial. Front Public Health. 2014;2:112.

43. Brantley MA Jr, Osborn MP, Sanders BJ, et al. The short-term effects of antioxidant and zinc supplements on oxidative stress biomarker levels in plasma: a pilot investigation. Am J Ophthalmol. 2012;153(6): 1104-1109. e2.

44. Pushpakumar SB, Kundu S, Metreveli N, Sen U. Folic acid mitigates angiotensin-II-induced blood pressure and renal remodeling. PLoS One. 2013;8(12):e83813. 


\section{Publish your work in this journal}

The International Medical Case Reports Journal is an international, peer-reviewed open-access journal publishing original case reports from all medical specialties. Previously unpublished medical posters are also accepted relating to any area of clinical or preclinical science. Submissions should not normally exceed 2,000 words or

4 published pages including figures, diagrams and references. The manuscript management system is completely online and includes a very quick and fair peer-review system, which is all easy to use. Visit http://www.dovepress.com/testimonials.php to read real quotes from published authors.

Submit your manuscript here: http://www.dovepress.com/international-medical-case-reports-journal-journal 